\title{
THE USE BY BIOLOGISTS AND ENGINEERS OF NON-SPECIALIST INFORMATION SOURCES AND ITS RELATION TO THEIR SOCIAL INVOLVEMENT
}

\author{
J. WILLEMS, ${ }^{*}$ E. WOUDSTRA** \\ * Faculty of Sciences, Nijmegen Catholic University (KUN), \\ P.O.B. 9010, 6500 GL Nijmegen (The Netherlands) \\ ** University of Twente (UT) (The Netherlands)
}

(Received April 23, 1993)

\begin{abstract}
Earlier investigations showed that many academics obtain information pertaining their own field of science from the general massmedia, such as newspapers. Who are those scientists? Is there a relation between the social engagement and the use of non-specialist information sources? We investigated the social engagement of biologists and engineers in correlation to their use of general massmedia in the Netherlands. Biologists find their work social significant, most of engineers do not. Many biologists are members of non-specialist organizations, subscribe to non-specialist journals about science and participate in non-scietific activities related to their work. Most engineers do not. Many members of both groups (biologists and engineers) use non-specialist informations sources like general science magazines and national newspapers to obtain information about their own field of science. And most biologists and engineers did so to obtain information about new developments in their own field and in related fields. We did not find any correlation between the social engagement of scientists and their use of non-specialist information sources. Most scientists use them.
\end{abstract}

\section{Introduction}

Scientists greatly depend on communication with fellow specialists. Research workers nearly always rely on the work of others; therefore they have to exchange information with specialists within the same field. Scientists not actively involved in research are also frequently searching for information on their specialism, or better, should be looking for such information. They also require up to date professional information in order to perform best. They should also be in a position to acquaint themselves with innovations in their field. 1,5

However, the amount of new information in any particular field is usually huge and still growing. This means that there is sometimes a large interval between discovery/formulation and publication. Furthermore, it can take a lot of time for the 
published information to reach the target group, which has to refer to an ever increasing number of different journals to keep up to date.

The interval between discovery/formulation, publication and target group exposure can be reduced considerably by employing non-specialized media such as newspapers and journals issued by different interest groups. Publication here is usually more rapid and the target group also employs such media for other purposes, for instance entertainment.

Studies into the communication of scientific and technological information usually address the dissemination of information through specialized scientific journals, conferences etc. Besides those channels, however, an important other circuit is in existence. According to $\mathrm{Rip}^{4}$ this includes sources like personal contacts, internal reports, and publications in popular science magazines and general scientific periodicals like Science and Nature.

Earlier investigations by Shaw et al., ${ }^{6} \mathrm{O}$ Keefe $e^{2}$ and Phillips et al. ${ }^{3}$ have shown that US academics (in this case physicians) also obtain information pertaining to their own field from the -general mass media, such as newspapers. So these media also form an important source of scientific information for scientists.

Investigations by Willems among biologists and chemists ${ }^{8}$ have shown that the same occurs in the Netherlands. Biologists and chemists also obtain information pertaining to their own field from non-specialist sources on a more or less regular basis.

Shaw et al. concluded that $60 \%$ of the physicians they had interviewed sometimes obtained information on their own field from the general mass media; in a similar survey, O Keefe established a figure of $89 \%$. In 1987 Willems found that $98 \%$ of the chemists and $97 \%$ of the biologists interviewed indicated they more or less regularly obtained information relevant to their field from the non-specialist media.

These surveys did not answer the question which scientists use such information regularly and which don't. Furthermore, the type of information obtained from the non-specialist literature was also not determined. It makes perhaps a difference whether a research worker obtains information about funds or relevant research data from the non-specialist literature.

There is a possibility that scientists active in applied fields will rely more on nonspecialist literature than scientists concentrating on fundamental research. After all, non-specialist literature generally contains more socially oriented information than scientific literature does. The hypothesis investigated in this survey is therefore: Scientists active in applied fields will generally use non-specialist literature more 
intensively to obtain information on their own field than scientists active in purely fundamental research.

To test the value of this hypothesis, a postal survey was held after pretesting the questions in the two targetgroups. It was involving a group of biologists and university-trained engineers. The biologists were included to enable a comparison with the earlier survey; the engineers were included because they usually work in strictly applied fields.

The names of the 450 biologists were obtained from the professional organization of biologists NIBI at Utrecht; the names of the 475 engineers were obtained from the address file of the students' and graduates' organization of Twente University.

The questionnaires were mailed in February and March 1991. Only the responses received within six weeks were included in the analysis. $68 \%(\mathrm{~N}=308)$ of the biologists and $50 \%(\mathrm{~N}=237)$ of the engineers have resr nded.

This has been a first attempt to investigate the r...y scientists gather information about their specialities. In spite of pretesting this survey therefore still contain some crude questions. Because of that the interpretation of the results should be considered with some caution.

The questionnaire included direct and indirect questions about:

- the respondents' social involvement;

- non-specialist information sources relevant to the respondent's occupation, and

- the nature of the collected information.

\section{Social involvement}

Before measuring the respondents' social involvement, we asked them directly how they assessed the social significance of their work.

More than half of the biologists think their work has a major social impact; only a small minority think their work is not socially relevant. Most engineers consider their work not to be of great social relevance, but they do not indicate this directly. They may find it difficult to answer this question; they do not reply or consider the question not to apply to their work.

If the work is socially relevant, what is its relevance? All respondents were asked to indicate the social significance of their work. 
Table 1

What is the direct social impact of your work?

\begin{tabular}{lrcrc}
\hline & \multicolumn{2}{c}{ Biologists } & \multicolumn{2}{c}{ Engineers } \\
\hline great & 116 & $37.7 \%$ & 26 & $11.0 \%$ \\
no so great & 87 & 28.2 & 24 & 10.2 \\
almost absent & 45 & 14.6 & 23 & 9.7 \\
absent & 22 & 7.1 & 7 & 3.0 \\
not applicable & 23 & 7.5 & 60 & 38.1 \\
no response & 15 & 4.9 & 66 & 28.0 \\
\hline
\end{tabular}

Table 2

What is the social significance of your work?

\begin{tabular}{|c|c|c|c|c|}
\hline \multirow[b]{2}{*}{ development of education } & \multicolumn{2}{|c|}{ Biologists } & \multicolumn{2}{|c|}{ Engineers } \\
\hline & 68 & $22.1 \%$ & 12 & $5.1 \%$ \\
\hline influence on policy-making & 93 & 30.2 & 17 & 7.2 \\
\hline advancement of well-being & 91 & 29.5 & 33 & 14.0 \\
\hline advancement of prosperity & 34 & 11.0 & 39 & 16.5 \\
\hline contribution to culture & 29 & 9.4 & 1 & 0.4 \\
\hline otherwise & 86 & 27.9 & 17 & 7.2 \\
\hline none & 15 & 4.9 & 41 & 17.4 \\
\hline no response & 10 & 3.2 & 108 & 45.8 \\
\hline
\end{tabular}

Most biologists identify with the first three categories; 'advancement of prosperity' scores little and apparently the concept of science as a cultural good also appeals to few. The engineers stick to their dislike of this sort of question.

Table 3

Are you a member of any non-specialist organization?

\begin{tabular}{lrrrr}
\hline & Biologists & \multicolumn{2}{c}{ Engineers } \\
\hline no & 30 & $9.7 \%$ & 71 & $30.1 \%$ \\
professional organization & 191 & 62.0 & 95 & 40.3 \\
union & 108 & 35.1 & 36 & 15.3 \\
political party & 29 & 9.4 & 22 & 9.3 \\
action committee & 36 & 11.7 & 9 & 3.8 \\
nature or environmental org. & 197 & 64.0 & 82 & 34.7 \\
& & & 45 & 19.1 \\
other & 35 & 11.4 & 50 & $21.2 \%$ \\
are you an active member? & 82 & $26.6 \%$ & & \\
\hline
\end{tabular}


In order to quantify the respondents' social involvement/orientation, they were asked whether they were members of non-specialist organizations and whether they subscribed to non-specialist scientific and technological journals. They were also asked about non-scientific activities within their own field.

Nearly all biologists are members of one or more non-specialist organizations. The engineers are far less active in this respect; nearly one third are not members of any non-specialist organizations. In terms of percentage, considerably fewer engineers than biologists are members of professional organizations, unions or nature and/or environmental societies. However, in view of the assumed lack of social relevance of the engineers' work (Tables 1 and 2), it is surprising to see that no less than one third of them are members of a nature or environmental society.

Table 4

What non-specialist journals do you subscribe to?

\begin{tabular}{lcccc}
\hline & \multicolumn{2}{c}{ Biologists } & \multicolumn{2}{c}{ Engineers } \\
\hline no & 46 & $14.9 \%$ & 117 & $49.6 \%$ \\
$\begin{array}{l}\text { Wetenschap \& Samenleving } \\
\text { (Science and Society) }\end{array}$ & 20 & 6.5 & 10 & 4.2 \\
$\begin{array}{l}\text { Natuur \& Techniek } \\
\text { (Nature and Technology) }\end{array}$ & 107 & 34.7 & 38 & 16.1 \\
$\begin{array}{l}\text { Milieudefensie } \\
\text { (Environmental defence) }\end{array}$ & 134 & 43.5 & 22 & 9.3 \\
Natuur \& Milieu & 116 & 37.7 & 15 & 6.4 \\
$\begin{array}{l}\text { Nature and Environment) } \\
\text { New Scientist }\end{array}$ & 38 & 12.3 & 10 & 4.2 \\
Nature or Science & 70 & 22.7 & 9 & 3.8 \\
Other & 100 & 32.5 & 60 & 25.4 \\
\hline
\end{tabular}

Many biologists read (or at least subscribe to) a number of non-specialist journals which relate indirectly to their profession. Both the popular science journal Natuur \& Techniek and the major environmental journals are favourites. Foreign general and popular science journals are slightly less popular, but more so than with the engineers.

Only half of the engineers subscribe to a non-specialized journal (on science and/or technology). 
Table 5

What non-scientific activities rejated to your field do you engage in?

\begin{tabular}{lrrrc}
\hline & \multicolumn{2}{c}{ Biologists } & \multicolumn{2}{c}{ Engineers } \\
\hline none & 166 & $53.9 \%$ & 166 & $70.3 \%$ \\
gives lectures & 70 & 22.7 & 31 & 13.1 \\
runs excursions & 39 & 12.7 & 11 & 4.7 \\
committee memberships & 55 & 17.9 & 31 & 13.1 \\
environmental campaigns & 39 & 12.7 & 4 & 1.7 \\
other & 43 & 14.0 & 11 & 4.7 \\
\hline
\end{tabular}

Most biologists and engineers are not involved in non-scientific activities such as popularizing their own field, campaigns, committee work and the like. This does not agree with the results of the 1991 survey results of Willems et al., ${ }^{9}$ which indicated that many (75\%) biologists are involved in popularizing their field of study.

\section{Use of non-specialist information sources}

One of the major objectives of this survey is to trace the use of non-specialist information sources within the scientists' field of study.

General science journals such as Nature and Science, journals of interest groups such as BioVision and Ingenieurskrant (Engineer's journal) and national newspapers (with science supplements) are important sources of professional information both for biologists and engineers.

For many biologists popular science journals also play an important part; engineers frequently mention controlled circulation magazines (Intermediair) and fairs and expositions as important media.

(Dutch) television is less important, but still scores impressive figures. The figures agree with those indicating the importance scientists attach to this medium in science popularization.7,9

Comparison of these figures with those found in the 1987 survey indicate some (minor) shifts. Apparently the general and popular science journals are consulted more frequently; the use of controlled circulation magazines, national newspapers and Dutch television programmes has decreased somewhat. 
Table 6

What non-specialist information sources are important for your work? (more than one entry possible)

\begin{tabular}{lrrrrc}
\hline & \multicolumn{2}{c}{ Biologists } & \multicolumn{2}{c}{ Engineers } & Biol/1987 \\
\hline general science journals & 140 & $45.5 \%$ & 84 & $35.6 \%$ & $32 \%$ \\
popular science journals & 120 & 39.0 & 53 & 22.5 & 26 \\
journals of interest groups & 180 & 58.4 & 146 & 61.9 & 51 \\
controlled circulation magaz. & 93 & 30.2 & 125 & 53.0 & 43 \\
newsmagazines & 34 & 11.0 & 20 & 8.5 & 9 \\
womens' magazines & 7 & 2.3 & 4 & 1.7 & 3 \\
national newspapers in gen. & 175 & 56.8 & 107 & 45.3 & 72 \\
nat. newsp. science supplem. & 196 & 63.6 & 107 & 45.3 & \\
regional newspapers in gen. & 35 & 11.4 & 30 & 12.7 & 11 \\
reg. newsp. science supplem. & 34 & 11.0 & 14 & 5.9 & \\
Dutch TV & 93 & 30.2 & 48 & 20.3 & 41 \\
foreign TV & 69 & 22.4 & 44 & 18.6 & 25 \\
radio & 19 & 6.2 & 10 & 4.2 & \\
fairs and expositions & 51 & 16.6 & 133 & 56.4 & \\
other & 36 & 11.7 & 21 & 8.9 & \\
\hline
\end{tabular}

Table 7

What sort of information do you usually obtain from these non-specialist media?

\begin{tabular}{lrrrc}
\hline & \multicolumn{2}{c}{ Biologists } & \multicolumn{2}{c}{ Engineers } \\
\hline new developments in own field & 213 & $69.2 \%$ & 155 & $65.7 \%$ \\
new developments in related fields & 221 & 71.8 & 166 & 70.3 \\
new developments in other fields & 163 & 52.9 & 115 & 48.7 \\
personal news & 101 & 32.8 & 65 & 27.5 \\
news on science policies & 124 & 40.3 & 64 & 27.1 \\
news on financial matters & 67 & 21.8 & 55 & 23.3 \\
social effects of biol. research & 201 & 65.3 & 88 & 37.3 \\
social effects of other research & 131 & 42.5 & 71 & 30.1 \\
soc. eff. on developing countries & 130 & 42.2 & 42 & 17.8 \\
\hline
\end{tabular}

During (oral) discussions following publication of the previous results, ${ }^{8}$ critics of this investigation suggested that biologists and chemists may consult non-specialist information sources, but that they undoubtedly do so to in order to obtain information on grants, appointments and the social consequences of scientific research. For scientific information on their own field of study, they would undoubtedly use the specialist literature. 
This survey indicates the opposite is true. When asked about the nature of the relevant information gathered from the non-specialist media, new developments in one's own field of study and in related fields score high!

\section{Analysis}

Analysis of the results indicates that nearly all biologists and engineers use nonspecialist media more or less frequently to gather information relevant to their profession. Only five per cent claims never to do so.

Table 8

How many sources of non-specialist information do you use?

\begin{tabular}{|c|c|c|c|c|c|c|}
\hline $\begin{array}{l}\text { Number of } \\
\text { non- } \\
\text {-specialist } \\
\text { information } \\
\text { sources }\end{array}$ & $\begin{array}{l}\text { Number of } \\
\text { biologists }\end{array}$ & $\%$ & Cumulative & $\begin{array}{l}\text { Number of } \\
\text { engineers }\end{array}$ & $\%$ & Cumulative \\
\hline 0 & 16 & $5.2 \%$ & - & 12 & $5.1 \%$ & - \\
\hline 1 & 32 & 10.4 & $15.6 \%$ & 21 & 8.9 & $14.0 \%$ \\
\hline 2 & 44 & 14.3 & 29.9 & 34 & 14.4 & 28.4 \\
\hline 3 & 42 & 13.6 & 43.5 & 47 & 19.9 & 48.3 \\
\hline 4 & 44 & 14.3 & 57.8 & 31 & 13.1 & 61.4 \\
\hline 5 & 47 & 15.3 & 73.1 & 31 & 13.1 & 74.6 \\
\hline 6 & 32 & 10.4 & 83.4 & 29 & 12.3 & 86.9 \\
\hline \multicolumn{7}{|l|}{$\cdot$} \\
\hline 12 & - & - & 99.0 & 1 & 0.4 & 100.0 \\
\hline 13 & 3 & 1.0 & 100.0 & & & \\
\hline
\end{tabular}

The social involvement of the respondents was determined by means of three questions regarding memberships of non-specialist organizations such as unions, action committees or environmental organizations, subscriptions to non-specialist scientific and technological journals, and participation in non-scientific activities related to one's own field.

In order to quantify this engagement, all respondents were assigned a score, calculated in the following way. 
For each question:

0 positive answers $=0$ points,

1 positive answer $=1$ point,

2 positive answers $=2$ points,

3 or more $\quad=3$ points.

In this way, each question can score at most three points, and three questions 9 points (= strong social engagement).

Table 9

Social involvement

\begin{tabular}{|c|c|c|c|c|c|c|}
\hline \multirow[b]{2}{*}{$\begin{array}{l}\text { Number } \\
\text { of points } \\
\text { scored }\end{array}$} & \multicolumn{3}{|c|}{ Biologists } & \multicolumn{3}{|c|}{ Engineers } \\
\hline & Number & $\%$ & Cumulative & Number & $\%$ & Cumulative \\
\hline 0 & 12 & $3.9 \%$ & - & 43 & $18.2 \%$ & - \\
\hline 1 & 23 & 7.5 & $11.4 \%$ & 44 & 18.6 & $36.9 \%$ \\
\hline 2 & 38 & 12.3 & 23.7 & 54 & 22.9 & 59.7 \\
\hline 3 & 40 & 13.0 & 36.7 & 43 & 18.2 & 78.0 \\
\hline 4 & 53 & 17.2 & 53.9 & 24 & 10.2 & 88.1 \\
\hline 5 & 48 & 15.6 & 69.5 & 15 & 6.4 & 94.5 \\
\hline 6 & 35 & 11.4 & 80.8 & 11 & 4.7 & 99.2 \\
\hline 7 & 25 & 8.1 & 89.0 & 2 & 0.8 & 100.0 \\
\hline
\end{tabular}

For the biologists, the median lies between 3 and 4 points, that is, near the centre. This is not the case for the engineers, where the median lies slightly below the score 2. This indicates that "on average" the engineers display little social engagement.

\section{Correlations}

In order to assess the relationships between some of these variables, correlations were calculated.

The correlation between field of study and media use (Table 6) was calculated to test the hypothesis.

According to the hypothesis, scientists with applied fields of study will make more use of non-specialist information sources than colleagues engaged in fundamental scientific research. This hypothesis was tested only for the biologists, because few of the engineers regard themselves as research workers. 
Speciality:

Correlation with media use:

microbiology/molecular biology

0.05

organismal biology

0.11

ecol./population biology

0.16 ( 1 tailed signif 0.01 )

general biology

0.13

other

0.01

There is little evidence of the assumed correlation between applied/fundamental specialities and media use. If such a relationship existed, a particularly large correlation with media use would have been found, especially in the categories of general biology (teachers? policy makers?) and/or "other". There is no such correlation.

The correlation between speciality and media use was calculated to test the hypothesis through another approach. According to the hypothesis, research workers (frequently active in fundamental research) will use the non-specialist media less intensively than, for instance, teachers and policy makers (rarely active in fundamental research).

Occupation:

Correlation with media use:

education

0.01

research

0.171 tailed signif 001

policy

0.06

other

0.07

This analysis also failed to confirm the hypothesis. On the contrary, only for the research workers a (small) correlation with the use of non-specialist information sources was discovered.

Another method of testing the hypothesis is by calculating the correlation between the social involvement of biologists/engineers (Table 9) and the use of nonspecialist media. A large degree of social engagement could indicate involvement in applied specialities. This correlation also failed to support the hypothesis; the coefficient is 0.09 . 


\section{Discussion}

Earlier research in the US and the Netherlands indicated that scientists more or less regularly employ non-specialist sources to collect information relevant to their own profession. The US investigation concerned physicians, the Dutch investigation concerned chemists and biologists. The US investigation focussed on the importance of newspapers, the Dutch investigation included a number of general and popular scientific sources.

This investigation confirms the earlier Dutch investigation carried out among biologists. Nearly all biologists collect information relevant to their own speciality from non-specialist media on a more or less regular basis. The media employed are more or less the same as those found in 1987.8 Only a few minor shifts were found: the general and popular science journals seem to have gained some popularity, whereas the controlled circulation magazines, national newspapers and Dutch television programmes seem to be used less frequently.

In this survey, the way university-trained engineers collect information was investigated for the first time. They, too, appear to make intensive use of nonspecialist media to collect information relevant to their own profession.

Nearly all biologists and engineers employ several non-specialist media, that is, if the general science journals such as Science or Nature are not included, an orientation towards these information sources still can be found.

Who are the users of non-specialist information sources which are relevant for their own work? Conceivably, generalists and scientists with applied specialities (teachers, managers, engineers) will make more use of such information sources than specialists (fundamental research workers). This investigation has shown that the use of non-specialist information sources is not limited to the first group; research workers employ non-specialist sources about as much as others.

It is also conceivable that socially engaged scientists will make more use of such information sources than colleagues who are not so socially engaged, because the general literature will contain more non-specialist information. This assumption is also ruled out by this study: the use of non-specialist information sources is evenly distributed over the respondents.

What information do the respondents obtain from these general and popular scientific sources? Conceivably it is used mainly for gathering professional information (personal and financial matters) and for information regarding other fields of study. This investigation has shown that scientists also gather information 


\section{J. WILLEMS, E. WOUDSTRA: NON-SPECIALIST INFORMATION SOURCES}

about their own work (for instance their own research projects) and adjacent fields from non-specialist sources. This is in keeping with the recently published study of Phillips et al., ${ }^{3}$ which describes the influence of non-specialist articles in the New York Times on citation counts in scientific literature.

\section{References}

1. J. Coleman et al., Medical Innovation. A Diffusion Study, New York, 1966.

2. M. O KEEFE, The mass media as sources of medical information for doctors, Journalism Quarterly, $47(1970) 95$.

3. D. Philurs et al., Importance of the lay press in the transmission of medical knowledge to the scientific community. NEJM 325-16 (1991) 1180.

4. A. Rip, Wetenschap als mensenwerk (Science as a human task), Baarn, Netherlands, 1978.

5. E. RoGERs, Diffusion of Innovations, London/New York, 1983.

6. D. SHAw et al., The information value of medical science news, Joumalism Quanerly, 44 (1967) 584.

7. J. WiLLEMS, Wetenschapsjournalistiek (Thesis), Nijmegen, 1976.

8. - Wetenschappers en hun niet-wetenschappelijke bronnen (Scientists and their non-scientific information sourcers), Wetenschap \& Samenleving, 9/10 (1987) 49.

9. - Bioloog populariseert niet uit eigenbelang (A biologist popularizes not for his own sake), BioNieuws (1991) 1-5. 